\title{
NPM and Change Management in Asset Management Organisations
}

\section{Purpose:}

Effective engineering asset management is essential in delivering public services safely whilst avoiding breakdowns and accidents. To ensure asset safety and sustainability, public sector firms have to adopt new processes and practices. It is the role of supervisors to implement the changes, and as part of the New Public Management (NPM) public sector reforms, public sector asset managers have more discretionary power to implement further changes related to increased accountability.

\section{Design/methodology/approach:}

The paper explores the impact of management practices on supervisor-employee relationships and employees' perception of autonomy, employees' attitudes toward change and their perceptions of organisational culture within Australian public sector engineering asset management organisations, and in the context of NPM reforms and consequent changes in supervisory discretionary power. Social exchange theory provided the theoretical framework and a self-report survey was administered to 149 employees.

\section{Findings:}

The findings from a structural equation model indicate positive and significant relationships between the variables in this study. A finding of significant interest was that public sector employees are on average slightly dissatisfied with their supervisors and feel they have a minimal amount of autonomy in the workplace. This may represent an unintended consequence of NPM reforms.

\section{Research implications:}

The implication of the findings is that an effective relationship between supervisors and employees is a necessary ingredient for achieving change, and ensuring asset safety and sustainability. Social exchange theorists argue that the low level of satisfaction with the supervisors evident in this study is one factor compromising asset safety and sustainability. 


\section{Originality/Value:}

The roadblocks to good supervisory relationships in the post NPM environment must be dismantled and the findings clearly indicate a need for targeted development of supervisors/management skills to ameliorate the negative effects of the NPM regime and enable effective change management.

Keywords: physical asset management, LMX, attitude toward organisational change, autonomy, proactive engineering asset management organisational culture (PEAMOC). 


\section{NPM and Change Management in Asset Management Organisations}

The public sector has experienced three decades of continual change resulting from the implementation of New Public Management (NPM). In theory, public sector reforms have aimed at improving organisational efficiency by improving management systems along with the implementation of budgetary controls, accountability, performance measures, outsourcing and a new focus on the customer (Diefenback, 2009). Another major change in the post NPM environment is the increased discretionary power of supervisors, especially in relation to managing professionals (Farr-Wharton et al., 2011). Brewer and Walker (2010) argue that the implementation of NPM can be the platform for increasing employee performance when effective management practices are used. Nonetheless, this outcome is not always achieved. Instead, within the Australian context, the implementation of NPM has been associated with significant reductions in per capita spending coupled with increased administration and monitoring by management. Such administration and monitoring has led to an increasing incidence of organisations characterised by inadequate resources (staff levels) and with increased level of organisational targets (Brunetto et al., 2012). However, the situation associated with NPM in public sector engineering asset management organisations has not been specifically examined.

A major source of organisational change within engineering asset management organisations, especially those delivering essential services (water, power, sewerage, transport), is that citizens (taxpayers) now expect longer asset longevity and a safe environment with minimal (or zero) disasters. Cagle (2003) defines engineering assets as those involving technical engineering expertise in both formation and maintenance of the asset. Significant and continual concerns exist across the globe because poor management of physical assets has been identified as a major contributor to accidents in critical assets such as 
power stations, oil rigs, etc. (Zuashkiani et al., 2011). Analysis of past infrastructure disasters, such as the recent Japanese power disaster, suggests the link between management practices and employee work practices (and especially the extent to which they undertake safety maintenance) is crucial for improving safety performance in engineering asset management organisations (Brunetto et al., 2013). In particular, past research has identified the importance of asset management organisational culture as a key determinant of performance (Cooksey \& Chae, 2011). Hence, the way employees are managed in engineering asset management organisations is changing based on the need for improved safety practices and behaviour (Zuashkiani et al., 2011), and increased managerial power as a result of the implementation of NPM (Diefenback, 2009). Researchers suggest that public sector managers do have more power than before NPM implementation (Brunetto et al., 2012; Diefenback, 2009), but the implications of this in terms of creating a proactive culture has not been examined within public sector engineering asset management organisations.

It is the supervisor's role in an organisation to implement (sometimes conflicting) organisational policies in such a way as to achieve the highest job performance from employees. Within the public sector context, supervisors are asked to reconcile the conundrum of poor resourcing in relation to expected performance targets. Effective supervisors are more likely to provide a work environment that promotes mutual reciprocity, such that supervisors engage in "helping behaviours" towards employees (Beattie, 2006) and as a consequence, employees are likely to have higher job performance (Cropanzano \& Mitchell, 2005). The overall problem is that these functions are, on average, performed poorly by public sector supervisors (Brunetto et al., 2012; Diefenback, 2009), perhaps because they lack the necessary skills and training to provide effective management.

This paper uses Social Exchange Theory (SET) as a lens to explore the impact of management practices on public sector employees' attitudes to change and subsequent 
outcomes. SET is used because it provides a framework for examining the potential outcomes from ideal workplace relationships, including those between supervisors and employees. Within the public sector, Brewer (2005) argues that, when supervisors are competent and skilful, the outcome is motivated, empowered employees and high organisational performance. Hassan and Hatmaker's (2014) study demonstrated a significant relationship between leadership (manager-employee relationships) and employee performance for public sector employees. This provides support for Cropanzano and Mitchell's (2005, p. 875) premise that "SET may well have the potential to provide a unitary framework for much of organizational behaviour”. Hence, we argue that the way supervisors manage is a vital discriminating variable in determining the attitude to change of public sector employees working in asset management. The research question guiding the study is:

What is the impact of supervisor-employee relationships and employees' perception of autonomy on employees' attitudes toward change and organisational culture in public sector engineering asset management organisations?

The next section provides a targeted literature review of relevant concepts which leads to the development of hypotheses. These are then tested and detailed in the results section and the explanation and implications of the findings are addressed in the discussion section.

\section{Background}

\section{Social Exchange Theory (SET)}

SET argues that when effective workplace relationships are in place, then resources, information and respect are shared as needed amongst all members (Cole et al., 2002). For employees, this means that they get greater access to knowledge, resources and respect; and for supervisors, it means that they receive support for their decisions, in return for offering support to employees. As a result, the organisation benefits because client and technical 
problems are resolved faster, with higher productivity and organisational effectiveness. Cropanzano and Mitchell (2005) argue that SET has the potential to explain much of the behaviour of different stakeholders within the organisation, including the relationship between the supervisor and the employee. We argue that, if the relationship between the supervisor and the employee is effective, then employees will feel empowered and positively attuned to implementing change and a positive, proactive organisational culture will result.

\section{Proactive Engineering Asset Management Organisational Culture (PEAMOC)}

PEAMOC is an important concept within engineering asset management organisations. Engineering asset management concerns the "depth and breadth of management issues associated with managing engineering assets including plant, equipment and infrastructure” (Reid \& Xerri, 2013, p. 73). Xerri and colleagues (2013, p. 2) propose that a PEAMOC is "one that encourages employees to use technical knowledge and monitoring to maintain assets before fatigue leads to equipment failure, so contributing to asset longevity”. However, it is widely held that many engineering asset management organisations typically have a reactive rather than proactive approach to engineering asset management, fixing equipment only when it fails (Brunetto et al., 2013).

Little is known about the antecedents and outcomes of a proactive culture in the context of engineering asset management, including knowledge about the role of workplace relationships in cultivating PEAMOC (Xerri et al., 2013). The present study aims to support development of relevant insights by testing the factors impacting on culture change (from a reactive to a proactive culture) in the context of public sector engineering asset management organisations, especially given the importance of NPM practices and procedures in such organisations. We argue that without PEAMOC, there is a grim prognosis for asset longevity and organisational performance, culminating in sub-optimal performance of engineering asset management organisations. This is because reactive approaches tend to be associated with 
poor organisational outcomes, including longer down-times, higher costs, lower asset reliability and greater unpredictability (Daley, 2008). On the other hand, proactive approaches to engineering asset management are considered to enhance organisational profitability and survival (Katičić \& Frković, 2010). The stark dichotomy between reactive and proactive engineering asset management presents a compelling reason to investigate ways to foment greater proactivity in engineering asset management, and Zuashkiani et al. (2011) urge further research to that end. Stephens (2010, p. 19), for example, describes a need for "a significant shift from the traditional maintenance philosophy and practice, often reactive in nature, to a proactive, well-planned process that is fully integrated”.

Presently, the road to engineering asset management proactivity is not clear. Stephens (2010) highlights the difficulty in making the shift to a more proactive engineering asset management system successful and enduring. The difficulty arises from the tendency to embed reactive engineering asset management approaches, resist organisational change, produce negative reinforcement loops (Zuashkiani et al., 2011), and the perpetuation of low maintenance productivity (Carroll et al., 1998). As Xerri et al. (2013, p. 2) explain, a reactive culture is more likely to have a negative impact on employees as it places them under pressure to rapidly fix failing assets, may require overtime and long working hours and may expose them to hazardous situations, potentially leading to accidents and even disasters.

\section{Supervisor-Employee relationships}

Leader-Member Exchange (LMX) theory is one way of capturing the supervisor-employee relationship. Within the broader SET framework, LMX theory argues that when the interactions between the supervisor and employees are effective, both parties begin to share resources, information, time and emotional support, which leads to the employees being given greater autonomy in decision-making, and control in their workplace (Wang et al., 
2005). Findings from a study conducted by Tummers and Knies (2013) in a public sector context suggests that positive relationships between managers and employees resulted in higher organisational commitment, greater work effort and enhanced empowerment. The role of leadership in creating these conditions, leading to meaningful work, as concluded by Tummers and Knies (2013), reinforces the importance of effective LMX at all levels of the organisation. Once a high quality LMX relationship is established, all stakeholders benefit (Mueller \& Lee, 2002). As such, management is increasingly concerned about ensuring high quality LMX is in place, because past research indicates that LMX predicts important employee outcomes such as discretionary power and affective commitment (Brunetto et al., 2011, 2012).

Research indicates that the relationship between supervisors and their subordinates is likely to be important in the development and maintenance of a proactive engineering asset management organisational culture (PEAMOC) (Xerri et al., 2013), by influencing attitudes toward change (Xerri, Nelson \& Brunetto, in press) and employee autonomy (Brunetto et al., 2012). According to Tsang (2002), empowered employees, good teamwork, communication, education and training, appropriate rewards and recognition, and a trust in management are all necessary ingredients for effective engineering asset management. LMX relationships can accordingly be expected to play an important role in maintaining PEAMOC.

Poor quality LMX relationships seem likely to constrain the proactive behaviour of employees and bring about low commitment and reactive engineering asset management. Though acknowledging the need for further confirmatory research, a recent study by Brunetto et al. (2013) supports the notion that a lack of support, information and resources hampers the ability of employees to work efficiently and effectively in engineering asset management organisations and this goes some way towards explaining the prevalence of reactive cultures in engineering asset management organisations. Based on past research, we expect that high 
quality LMX will support previous research and show that it is directly associated with high perceptions of employee autonomy (Brunetto et al., 2012), PEAMOC (Xerri et al., 2013), and positive attitudes toward change.

H1: LMX will be positively associated with high perceptions of employee autonomy.

H2: LMX will be positively associated with attitude towards change.

H3: LMX will be positively associated with a PEAMOC.

\section{Employees' perception of Autonomy}

Farr-Wharton et al. (2011) found that LMX was positively correlated with nurses' and engineers' perception of autonomy. In addition, Volmer et al. (2011) conclude that job autonomy mediates the relationship between LMX and creative work behaviour. Past research suggests that one antecedent of autonomy is the quality of workplace relationships, especially in the case of engineers where supervisor-engineer relationships were found to affect autonomy and affective commitment (Farr-Wharton et al., 2011). Also, employees' perceptions of autonomy have been found to contribute to organisational effectiveness (Thompson \& Prottas, 2006). In this study, it is argued that empowered employees who can act autonomously in the organisation are more likely to act proactively in undertaking engineering asset management activities.

\section{Attitude to Change}

Research supports the logical proposition that an employee's attitude toward change is influenced by the nature of the relationships that exist between management and their employees. If change is implemented poorly, it can reduce organisational performance (Chawla \& Kelloway, 2004). Beer and Nohria (2000) outline that up to 70 per cent of organisations that have attempted to implement organisational change have failed, sometimes 
because the messages from management are poorly communicated or badly managed (FarrWharton et al., 2011).

When considering changing organisational culture, there may be a further level of complexity added, that is, changing culture is a difficult task because it is embedded into organisational norms and values (Parker and Bradley, 2000). As Zuashkiani et al. (2011, p. 85) claim, organisational culture is difficult to change because it is established over a lengthy period and becomes embedded, making it hard for an engineering asset management organisation to move from a reactive approach to a proactive one. However, Cunningham et al. (2002) noted the role of employee empowerment, arguing that organisational change is more likely to be successfully implemented if employees felt empowered and perceived that they had social support within the organisation. Chrusciel (2008) argues that change initiatives are accomplished through team effort.

Given that LMX relationships are positively associated with affective outcomes such as stronger organisational commitment and higher overall satisfaction (Gerstner \& Day, 1997), and that LMX relationships are considered to be particularly important within engineering organisations (Lee et al., 2005), it is reasonable to anticipate that LMX relationships will influence attitudes toward change, especially regarding the movement toward, and reinforcement and retention of proactive engineering asset management organisational culture. Support for this proposition is found in a study of LMX in SMEs conducted by Farr-Wharton and Brunetto (2007), which found that the nature and quality of the relationships between employees and their superiors significantly influenced communication flows and provided the support, feedback and respect that helped to allay fears about change and facilitate acceptance of change.

H4: Attitude to change will be positively associated with employee perceptions of autonomy. 
H5: Attitude to change will be positively associated with a PEAMOC.

H6: Employees' perception of autonomy will be positively associated with a PEAMOC.

\section{METHODS}

An Australian market research company was employed to attain a sample of asset managers and employees working within engineering asset management organisations. In particular, an email containing a link to an online survey, using the survey monkey tool, was sent to 1012 members who were employed in organisations charged with the management of physical assets. To rule out unsuitable members, each respondent was asked about their job in relation to the physical management of assets; those who were not directly involved with the physical management of assets were informed that they did not meet the requirements of the study. A total of 255 suitable employees responded from the private and public sector, there were a total of 149 public sector respondents and 107 were a male, which is an accurate representation of the engineering profession in Australia, considering that females make up only 10.6 per cent of the engineering workforce in Australia (Kaspura, 2012). The age distribution of the employees examined are aligned with the age distribution in the engineering sector, which provides some support that the small sample appears to be representative of the wider population. For example, 21 (14.1\%) of the employees sampled and 18.1 per cent of the engineering sector were less than 30 years old, 77 (51.7\%) of the employees sampled and 41.46 per cent were aged 30-45, and 55 (34.2\%) employees survey and 40.44 per cent of the sector were older than 45 (Engineers Australia, 2014).

\section{Measures}

A six-point scale was used, ranging from ' 1 '=strongly disagree to ' 6 '=strongly agree. The quality of the supervisor-subordinate relationship was measured using the LMX-7 scale developed by Graen and Uhl-Bien (1995). Autonomy was measured with a three-item scale, using the self-determination questions from Spreitzer's (1995) measure of empowerment. 
PEAMOC was measured using a six-item scale developed by Xerri et al. (2013). To measure affective attitude toward change, we used 6-items from the 18-item attitude toward change scale developed by Dunham (1989). The 18-item attitude toward change scale includes three dimensions: affective (how an employee feels about the change initiative), cognitive (what an employee thinks about a change initiative), and behavioural (employee actions or intended actions as a result of the change). While each dimension provides insight into an employee's attitude toward change, this study will focus on an affective attitude toward change because the theme of the study relates to how an employee feels about a number of concepts, for example, the relationship with their leader, their experience of workplace autonomy and perceptions of current organisational culture.

Control variables included age, gender, position in company and education level. Employee education level was measured by asking respondents to list their highest educational qualification. Employee education and their position in the organisation have been included as control variables because they may influence employee perceptions. As one example, employees in different positions in the organisation may have different perceptions of organisational culture. As well, there is research to suggest that generational differences (age) may influence employee perceptions in the workplace (Leiter, Price \& Spence-Laschinger, 2010), so we controlled for age. There is also support that engineering in Australia is a male dominated profession (Engineering Australia, 2014), which provides support that gender may influence employee perceptions of organisational culture and should be controlled.

\section{Data analysis}

Analysis of Moment Structures (AMOS) v.20 software, structural equation modelling (SEM), was used to tests the hypotheses. The Statistical Package for Social Sciences (SPSS) v.20 was used to calculate a number of descriptive statistics. The two-step approach to SEM by 
Anderson and Gerbing (1988) was used in this study. To determine model-fit, a number of indices were used: chi-square ratio $\left(\chi^{2} / \mathrm{df}\right)$, which should be less than 3 (Hair et al., 2010); comparative fit index (CFI) (Bollen, 1989); and Tucker-Lewis index (TLI) (Tucker and Lewis, 1973), which should be $>0.90$ for an adequate fit or $>0.95$ for a superior fit (Byrne, 2010); and the root-mean-square error of approximation (RMSEA), which should be $<0.08$ for an adequate fit or below 0.05 for a superior fit (Steiger, 1989). Maximum-likelihood estimation technique was used and the results from a statistical test of Skewness and Kurtosis provided support that the data was univariate normal. To improve multivariate normality, six cases were removed from the dataset, which reduced the useable sample size to $\mathrm{N}=149$. Mardia’s $(1970,1974)$ normalised estimate of multivariate kurtosis was close to the cut-off value of 5 (Bentler, 2005), indicating multivariate normality.

\section{Validity and reliability}

In an attempt to reduce the issues associated with common method bias, the measurement of the criterion and predictor variables were physically separated in the survey, as well the survey was completely anonymous (Podsakoff et al., 2003). Additionally, a common latent factor was added to the structural model (see Table 4), and the result was an adequate fitting model where all paths that were previously significant remained as such (Podsakoff et al., 2003).

The Confirmatory Factor Analysis (CFA) provides supporting evidence that the data is reliable and valid. Following the modification of the measurement model, all factor loadings were greater than 0.70 and none exceeded one. As depicted in Table 2, average variance extracted (AVE) and composite reliability exceeded 0.50 and 0.70 respectively (Hair et al., 2010). The data also has discriminant validity as the square root of the AVEs is greater than the intercorrelation between other constructs (see Table 2). 


\section{Results}

\section{Confirmatory Factor Analysis}

The hypothesised measurement model provided a reasonably poor fit $\left(\chi^{2} / \mathrm{df}=2.14\right.$, CFI $=.90$ TLI $=.89$, RMSEA $=.09$ ). A review of the findings revealed that one observed item from the LMX scale (My supervisor recognises my potential) and one from the attitude toward change scale (Most of my co-workers benefit from change) had a low squared multiple correlations (.035 and .147 respectively), so these items were removed from the model. Following the modification of the measurement models $\left(\chi^{2} / \mathrm{df}=1.92, \mathrm{CFI}=.94\right.$, TLI $=.93$, RMSEA $=.08)$, there was an adequate model fit.

Three competing models were tested and the results indicate that the 4-factor model provided a good fit that was superior to the 2- and 3-factor models (see Table 4). As well the delta chi-squares $\left(\Delta \chi^{2}\right)$ provide supporting evidence that the 5-factor model is an improvement over the 3- and 4-factor models; that is, they were statistically significantly different.

\section{Descriptions and Correlations}

Table 2 shows that PEAMOC is not significantly related to LMX or autonomy; but all other factors are significantly related to each other.

\section{Testing the hypotheses}

Figure 1 depicts support for all of the hypotheses. The control variables age, gender, positions in company and education level were not significantly related to innovative behaviour, so they were removed from Figure 1. The results as depicted in Figure 1 show that LMX predicted 30.3 per cent of the variance of employees' perception of autonomy, and LMX and autonomy predicted 34.6 per cent of the variance of employee attitudes toward 
change. As well, LMX, autonomy and attitudes toward change predicted 64.1 per cent of the variance of an employee's perception of PEAMOC.

\section{Discussion and implications}

The aim of this paper was to explore the impact of management practices on supervisoremployee relationships and employees' perception of autonomy, employees' attitudes toward change and their perceptions of organisational culture within Australian public sector engineering asset management organisations. The context of the changes discussed is an increasing discretionary power of supervisors caused by implementation of New Public Management (NPM) and the premise that effective public sector management leads to increased job performance (Brewer \& Walker, 2010), although, not often because of poor training and unrealistic target performance coupled with inadequate resourcing (Brunetto et al., 2012).

The results of the SEM model indicate that the paths from management (LMX) to: (a) employees' attitude to change, (b) their perception of autonomy and (c) whether employees operate in a proactive or reactive maintenance culture are all significant. Hence, the quality of management is important for influencing how employees address change, how autonomous they feel and whether or not employees are encouraged to proactively maintain assets before accident or fatigue leads to equipment failure. However, the results depict that engineering asset management public sector employees seem to be somewhat dissatisfied with management/supervisor relationships (See Table 2). In particular, the mean results for employee satisfaction with their supervisor and their perception of autonomy are low. These findings may indicate that the impact of NPM on both LMX and organisational culture result in reduced supervisory scope for decisions and higher levels of red tape, in terms of the NPM requirement to follow documented procedures. In summary, the findings support the work of Diefenback (2009) and Brunetto et al. (2012), who argued that the implementation of NPM 
had negative implications for the quality of management and in turn the quality of the culture in the organisation.

There are two major implications of these findings. Firstly, at a time in Australia when there is an overall shortage of engineers and public sector organisations are finding it particularly difficult to attract engineers (Brunetto et al., 2013), these findings provide an important new contribution to understanding the reasons why this is so. Without management support and leadership, the work environment is difficult to negotiate, especially when it is a struggle to get resources and information just to undertake everyday tasks (Brunetto et al., 2012, 2013). Secondly, these findings suggest that public sector asset management organisations are somewhat unsupportive of building a proactive organisational culture and this could have negative repercussions for public sector asset longevity and asset breakdowns (such as water, sewage, trains etc.), as well as associated costs. In contrast, best-practice evidence suggests that asset sustainability requires management and supervision that promotes a proactive culture, so that asset performance and fatigue is monitored and addressed long before a safety or fatigue issue arises (Brunetto et al., 2013). Research evidence suggests a strong connection between leadership and performance (Hassand \& Hatmaker, 2014) and leadership and the provision of meaningful work (Tummers \& Knies, 2013) in the public sector. It appears that NPM has not delivered a management approach that is conducive to achieving proactive engineering asset management organisational culture (PEAMOC). Instead, the findings provide evidence that, from an employee's perspective, the way NPM has been implemented, coupled with the reduced funding regime in the public sector and a level of accountability that has multiplied red tape (Brewer et al., 2010), current engineering asset management practices in the public sector may not be effectively mobilised for achieving optimum asset safety and longevity. 
Further, the findings indicate that public sector employees' attitudes to change reflect their perceptions of autonomy, their attitudes towards change and whether or not organisational culture is geared towards proactive or reactive work. Encouragingly, the findings indicate that employees had an attitude to change, coupled with a sense that their organisational culture was somewhat proactive, which provides a positive indication that public sector asset management organisations have in place some processes, at least, that proactively maintain assets and ensure that basic safety levels are maintained.

One clear contribution of this paper is that it has identified features of the management culture required for effective and proactive asset management. Previous research had identified that LMX predicted organisational asset management culture (Brunetto et al., 2013) and this study confirmed those findings. However, this study also identified that employees' attitude towards change and their perception of autonomy was significantly related to organisational asset management culture. These findings suggest that if the leadership of asset management organisations wishes to promote a proactive organisational culture, then it will need to pay significant attention to improving the quality of LMX, enhancing supervisors' and employees' autonomy and building a change ready environment in an organisation. The implications for supervisory practice clearly indicates a need for targeted development of supervisor team leading/management skills, including conduct of participative team meetings, team-based problem-solving processes, development of participative decision-making, communication and feedback skills and facilitation of workplace innovation. It is clear that an investment in human capital at every level of engineering asset management organisations is required to ameliorate the more negative effects of the NPM regime, enable effective change management and build proactive organisational cultures to support effective use and maintenance of engineering assets. 
Interestingly, based on the findings, while public sector engineering asset management employees perceive themselves to be lacking in autonomy, they nevertheless perceive that they work in a somewhat proactive culture or PEAMOC. However, employees' perception of autonomy was quite low, suggesting that the combination of rules, regulations, red tape and accountability work against them having the autonomy to be effective in a 'resource-scarce' workplace. Scotti et al. (2007) argue that autonomy is essential for employees working in resource-constrained environments so that they could find innovative ways of addressing problems. Without a perception and experience of autonomy, it is likely that public sector engineering asset management employees will find it more difficult to be effective in their workplace, which weakens organisational effectiveness.

\section{Conclusion}

This study used Social Exchange Theory (SET) as a lens to explore the impact of NPM on supervisor-employee relationships and employees' perception of autonomy, employees' attitudes toward change and their perceptions of organisational culture within Australian public sector engineering asset management organisations. SET predicts that, under ideal conditions, an effective supervisor-employee relationship delivers benefits to all stakeholders (employees, supervisors, organisation, and the public). Using SET, the findings show evidence of employees being somewhat dissatisfied with the relationship they have with their supervisor and therefore management, suggesting that they are not being given access to necessary resources and information as required for them to do their job effectively. This has negative implications - it affects public sector employees' attitude towards change as well as their perception of being members of a proactive organisation (PEAMOC), which in turn affects the extent to which employees are willing and able to maintain assets for safety and 
longevity. This in turn affects the public in the form of (restricted) services and the funds necessary to fix or replace expensive infrastructure.

The way forward, to ensure a more effective public sector asset management regime, is to remove the obstacles and roadblocks to good management in the post NPM environment, away from the processes identified by Diefenback (2009) and invest in the human capital, or human assets of the organisation by moving towards a leadership/management approach that prizes and promotes effective workplace relationships,

Limitations and future research

There were a number of limitations pertaining to the methods of the study that should be considered when interpreting the findings. First, there is a concern that modifying the models to improve fit may produce sample specific results (Byrne, 2010). In particular, the problem is that researchers may act opportunistically and capitalise on chance opportunities to increase model-fit. The capitalisation of chance opportunities is not good for replicability and generalisability, because this may see a relationship in one sample that is not present in other similar samples. Due to the fact that the sample size for this study was too small to allow for cross-validation, this poses a limitation to the study. Further studies with larger numbers are required to address this limitation. Also, the study requires validation in other countries. Second, the data was cross-sectional in nature, marking it less applicable to generalise causal relationships. Therefore, further research is also required to be able to generalise these results to the engineering asset management profession.

\section{REFERENCES}

Anderson, J. C., \& Gerbing, D. W. (1988), "Structural equation modeling in practice: A review and recommended two-step approach”, Psychological Bulletin, Vol. 103 No. 3, pp. 411-423.

Beattie, R.S. (2006), “Line managers and workplace learning: Learning from the voluntary Sector”, Human Resource Development International, Vol. 9 No. 1, pp. 99-119. 
Beer, M., \& Nohria, N. (2000). Cracking the Code of Change. Harvard Business Review, 78(3), 133-141.

Brewer, G. (2005), "In the Eye of the Storm: Frontline Supervisors and Federal Agency Performance”, Journal of Public Administration Research and Theory, Vol. 15, pp. 505-527.

Brewer, G.A., and R.M. Walker. (2010), "Explaining Variation in Perceptions of Red Tape: A Professionalism-Marketization Model " Public Administration,Vol. 88, No. 2, pp. 418-38.

Brunetto, Y., Farr-Wharton, R., Shacklock, K., \& Robson, F. (2012), "Supervisor relationships, teamwork, role ambiguity and discretionary power: nurses in Australia and the United Kingdom”, International Journal of Public Administration, Vol. 35 No. 8, pp. 532-543.

Brunetto, Y., Farr-Wharton, R., \& Shacklock, K. (2011). "Using the Harvard HRM model to conceptualise the impact of changes to supervision upon HRM outcomes for different types of public sector employees " International Journal of Human Resource Management 22(3), 553-573.

Brunetto, Y., Xerri, M., \& Nelson, S. (2013), "Building a proactive, engagement culture in asset management organizations”, Journal of Management \& Engineering. Doi: 10.1061/(ASCE)ME.1943-5479.0000251

Cagle, R. (2003), “Infrastructure asset management: An emerging direction”, Paper presented at the AACE International Transactions.

Carroll, J., Sterman, J., \& Marcus, A. (1998), "Playing the maintenance game: How mental models drive organizational decisions”, Debating rationality: Nonrational elements of organizational decision making, pp. 99-121.

Cole, M., Schaninger, W., \& Harris, S. (2002), “The Workplace Social Exchange Network”, Group \& Organization Management, Vol. 27 No. 1, pp. 142-167.

Cooksey, S. R., \& Chae, M. J. (2011), “Asset Management Assessment Model for State Departments of Transportation”, Journal of Management in Engineering, Vol. 27, pp. 159-169.

Chawla, A., \& Kelloway, E. K. (2004), "Predicting openness and commitment to change”, Leadership \& Organization Development Journal, Vol. 25 No. 6, pp. 485-498.

Chrusciel, D. (2008), “What motivates the significant/strategic change champion(s)?”, Journal of Organizational Change Management, Vol. 21 No. 2, pp.148-160.

Cropanzano, R. and Mitchell, M.S. (2005), "Social exchange theory: an interdisciplinary review”, Journal of Management, Vol. 31, pp. 874-900.

Cunningham, C. E., Woodward, C. A., Shannon, H. S., MacIntosh, J., Lendrum, B., Rosenbloom, D., \& Brown, J. (2002), "Readiness for organizational change: a longitudinal study of workplace, psychological and behavioural correlates”, Journal of Occupational \& Organizational Psychology, Vol. 75 No. 4, pp. 377-392.

Daley, D. T. (2008), The Little Black Book of Maintenance Excellence: Industrial Press Inc.

Engineers Australia. (2014). The engineering workforce: Engineers Australia's response to the AWPA issues paper. 
Farr-Wharton, R., \& Brunetto, Y. (2007), “Organisational relationship quality and service employee acceptance of change in SMEs: A social exchange perspective”, Journal of Management and Organization, Vol. 13 No. 2, pp. 114-125.

Farr-Wharton, R., Brunetto, Y., \& Shacklock, K. (2011), "Professionals' supervisorsubordinate relationships, autonomy and commitment in Australia: a leader-member exchange theory perspective" International Journal of Human Resource Management, Vol. 22 No. 17, pp. 3496-3512.

Gerstner, C. R., \& Day, D. V. (1997), "Meta-Analytic Review of Leader-Member Exchange Theory: Correlates and Construct Issues”, Journal of Applied Psychology, Vol. 82 No. 6, pp. 827-844.

Hair, J. F., Black, W. C., Babin, B. J., \& Anderson, R. E. (2010), Multivariate data analysis: A global perspective. Upper Saddle River, New Jersey: Pearson Education.

Hassan, S., \& Hatmaker, D. M. (2014). "leadership and performance of public employees: effects of the quality and characteristics of manager-employee relationships”, Journal of Public Administration Research and Theory, early view.

Kaspura, A. (2012), The engineering profession: a statistical overview. Barton, Australian Capital Territory: Engineers Australia

Katičić, L., \& Frković, D. (2010), “Distinction of facility and asset management in Croatia.” Paper presented at the The 5th World Congress on Engineering Asset Management.

Lee, T. S., Lee, D. W., Lee, H., \& Park, H. S. (2005), "Superior-subordinate relationships in Korean civil engineering companies”, Journal of Management in Engineering, Vol. 21 No. 4, pp. 159-163.

Leiter, M. P., Price, S. L., \& Spence-Laschinger, H. K. (2010). Generational differences in distress, attitudes and incivility among nurses. Journal of Nursing Management, 18(8), 970-980.

Mueller, B. H., \& Lee, J. (2002), “Leader-member exchange and organizational communication satisfaction in multiple contexts", Journal of Business communication, Vol. 39 No. 2, pp. 220-244.

Parker, R., \& Bradley, L. (2000). Organisational culture in the public sector: evidence from six organisations. International Journal of Public Sector Management, 13(2), 125-141.

Podsakoff, P. M., MacKenzie, S. B., Lee, J. Y., \& Podsakoff, N. P. (2003), "Common method biases in behavioral research: a critical review of the literature and recommended remedies", Journal of Applied Psychology, Vol. 88 No. 5, pp. 879-903.

Reid, S. R. M., \& Xerri, M. J. (2013), "The 'state of play' in engineering asset management: towards a conceptual frame”, International Journal of Engineering Management and Economics, Vol. 4 No. 1, pp. 72-83.

Scotti, D. J., Harmon, J., \& Behson, S. J. (2007), “Links among high-performance work environment, service quality, and customer satisfaction: an extension to the healthcare sector”, Journal of healthcare management/American College of Healthcare Executives, Vol. 52 No. 2, pp. 109-124.

Steiger, J. H. (1989). EzPATH: A supplementary module for SYSTAT and SYGRAPH. Evanston, IL: Systat, 1.

Stephens, M. P. (2010). Productivity and reliability-based maintenance management: Purdue University Press. 
Thompson, C. A., \& Prottas, D. J. (2006), "Relationships among organizational family support, job autonomy, perceived control, and employee well-being”, Journal of Occupational Health Psychology, Vol. 11 No. 1, pp. 100-118.

Tsang, A. (2002), “Strategic dimensions of maintenance management”, Journal of Quality in Maintenance Engineering, Vol. 8 No. 1, pp. 7-39.

Tummers, L. G., \& Knies, E. (2013), “Leadership and meaningful work in the public sector”, Public Administration Review, Vol 73 No. 6, pp. 859-868.

Volmer, J., Spurk, D., \& Niessen, C. (2011), “Leader-member exchange (LMX), job autonomy, and creative work involvement”, The Leadership Quarterly, Vol. 23 No. 3, pp. 456-465.

Wang, H., Law, K. S., Hackett, R. D., Wang, D., \& Chen, Z. X. (2005), “Leader-member exchange as a mediator of the relationship between transformational leadership and followers' performance and organizational citizenship behavior”, Academy of Management Journal, Vol. 48 No. 3, pp. 420-432.

Xerri, M. J., Nelson, S. A., \& Brunetto, Y. (2013), “Cutting thorugh red tape: putting an end to the thwarting of proactive engineering asset management”, Paper presented at the World Congress on Engineering Asset Management (WCEAM), Hong Kong.

Xerri, M., Nelson, S. \& Brunetto, Y. (in press), The importance of workplaces relationships and attitudes toward organizational change in engineering asset management organizations. Journal of Management in Engineering.

Zuashkiani, A., Rahmandad, H., \& Jardine, A. K. S. (2011), "Mapping the dynamics of overall equipment effectiveness to enhance asset management practices”, Journal of Quality in Maintenance Engineering, Vol. 17 No. 1, pp. 74-92. 
Table 1: Demographics

\begin{tabular}{lcc}
\hline Gender & $\mathbf{N}$ & $\mathbf{\%}$ \\
Male & 107 & 71.8 \\
Female & 42 & 28.2 \\
Age & & \\
$=<30$ years & 21 & 14.1 \\
31-44 years & 77 & 51.7 \\
45+ years & 51 & 34.2 \\
Position & & \\
Asset manager & 103 & 69.1 \\
Asset engineer & 22 & 14.8 \\
Asset maintenance & 24 & 16.1 \\
\hline $\mathrm{N}=149$ & & \\
\hline
\end{tabular}

Table 2: Descriptive statistics and correlations

\begin{tabular}{|c|c|c|c|c|c|c|c|c|c|c|c|}
\hline & Mean & S.D. & C.R. & $\alpha$ & 1 & 2 & 3 & 4 & 5 & 6 & 7 \\
\hline 1. LMX & 3.97 & .80 & .90 & .87 & $(0.80)$ & & & & & & \\
\hline $\begin{array}{l}\text { 2. Attitude } \\
\text { toward change }\end{array}$ & 4.42 & .71 & .84 & .84 & $.476^{* *}$ & $(0.78)$ & & & & & \\
\hline 3. Autonomy & 3.99 & .91 & .93 & .93 & $.493^{* *}$ & $.428^{* *}$ & $(0.93)$ & & & & \\
\hline 4. PEAMOC & 4.31 & .82 & .93 & .89 & -.102 & $.186^{*}$ & -.025 & $(0.88)$ & & & \\
\hline 5. Age & - & - & - & - & .029 & .077 & .149 & -.040 & & & \\
\hline 6. Gender & - & - & - & - & .106 & .103 & .156 & .068 & -.030 & & \\
\hline 7. Position & - & - & - & - & -.134 & -.136 & .046 & .047 & .090 & .086 & \\
\hline 8. Education & - & - & - & - & .025 & .108 & -.011 & .051 & $-.293 * *$ & .049 & -.077 \\
\hline
\end{tabular}

*. Correlation is significant at the 0.05 level (2-tailed).

**. Correlation is significant at the 0.01 level (2-tailed).

C.R. = composite reliability; $\alpha=$ Cronbach's alpha; Square root of AVE in parentheses

Table 4: Model fit

\begin{tabular}{llccc}
\hline & $\chi^{2} / \mathbf{d f}$ & CFI & TLI & RMSEA \\
\hline Public & & & & \\
Measurement model & 2.14 & .900 & .886 & .088
\end{tabular}




$\begin{array}{lcccc}\text { Respecified measurement model } & 1.92 & .940 & .928 & .079 \\ \begin{array}{l}\text { Adds common method variance to } \\ \text { respecified measurement model }\end{array} & 1.65 & .963 & .949 & .066 \\ \begin{array}{l}\text { 2-factor model - LMX \& autonomy } \\ \text { removed }\end{array} & 2.66 & .935 & .914 & .106 \\ \begin{array}{l}\text { 3-factor model- LMX removed } \\ \text { 4-factor model (All hypothesised paths) }\end{array} & 2.20 & .944 & .929 & .090 \\ \end{array}$

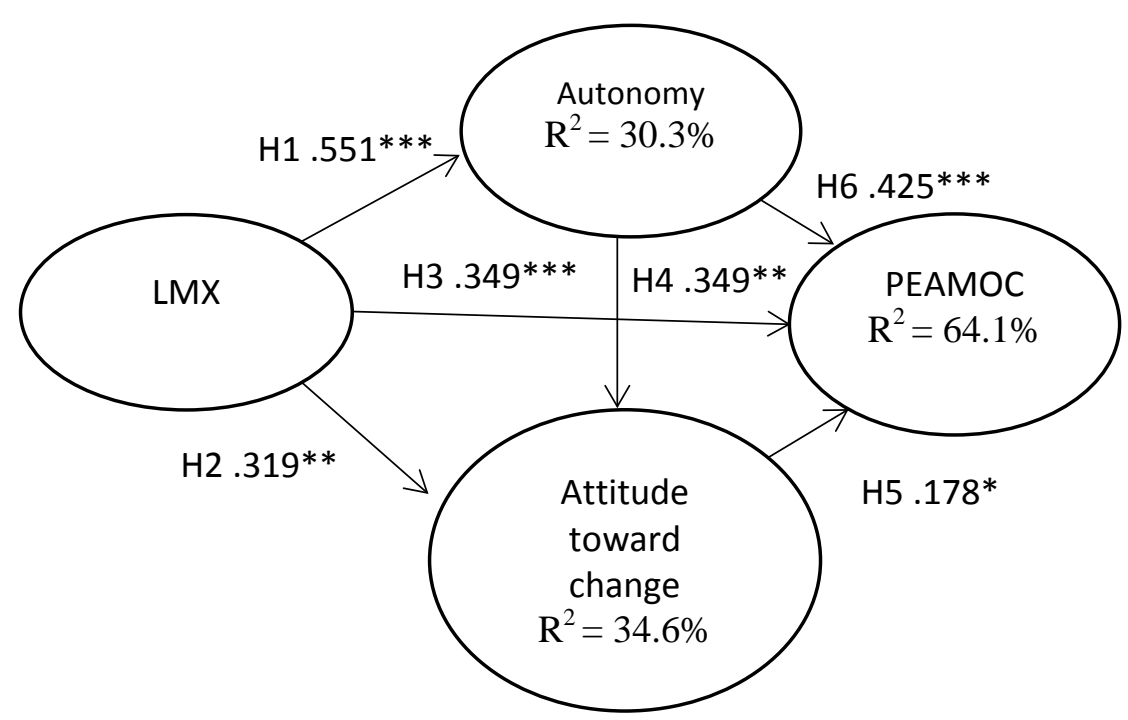

*. Significant at the 0.05 level (2-tailed).

**. Significant at the 0.01 level (2-tailed).

***. Significant at the 0.001 level (2-tailed).

Figure 1. Path model of factors influencing proactive engineering asset management organisational culture of public sector asset management employees 